\title{
Feasibility of an Interactive Health Coaching Mobile App to Prevent Malnutrition and Muscle Loss in Esophageal Cancer Patients Receiving Neoadjuvant Concurrent Chemoradiotherapy: Prospective Pilot Study
}

Kyungmi Yang ${ }^{1}$, MD, PhD; Dongryul $\mathrm{Oh}^{1}$, MD, PhD; Jae Myoung Noh ${ }^{1}, \mathrm{MD}$, PhD; Han Gyul Yoon ${ }^{1}$, MD; Jong-Mu $\mathrm{Sun}^{2}$, MD, PhD; Hong Kwan Kim³ ${ }^{3}$ MD, PhD; Jae Ill Zo ${ }^{3}$, MD, PhD; Young Mog Shim³ , MD, PhD; Hyunyoung $\mathrm{Ko}^{4}$, MSc; Jungeun Lee ${ }^{4,5}, \mathrm{PhD}$; Youngin $\mathrm{Kim}^{6,7}$, MD

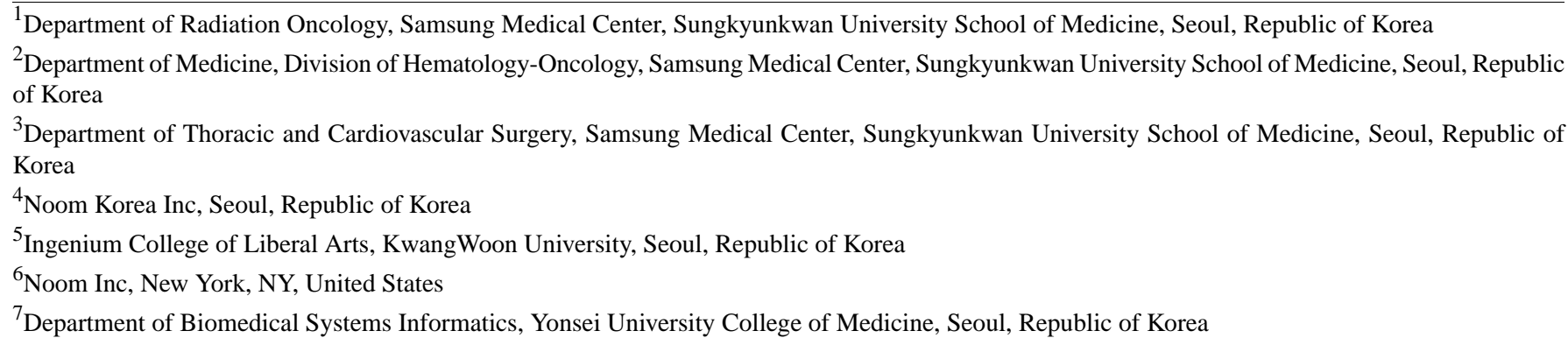

Corresponding Author:

Dongryul Oh, MD, PhD

Department of Radiation Oncology

Samsung Medical Center

Sungkyunkwan University School of Medicine

81 Irwon-ro

Gangnam-gu

Seoul, 06351

Republic of Korea

Phone: 82234102612

Fax: 82234102619

Email: dongryul.oh@ samsung.com

\begin{abstract}
Background: Excessive muscle loss is an important prognostic factor in esophageal cancer patients undergoing neoadjuvant chemoradiotherapy (NACRT), as reported in our previous research.

Objective: In this pilot study, we prospectively tested the feasibility of a health coaching mobile app for preventing malnutrition and muscle loss in this patient population.

Methods: Between July 2019 and May 2020, we enrolled 38 male patients with esophageal cancer scheduled for NACRT. For 8 weeks from the start of radiotherapy (RT), the patients used Noom, a health coaching mobile app that interactively provided online advice about food intake, exercise, and weight changes. The skeletal muscle index (SMI) measured based on computed tomography and nutrition-related laboratory markers were assessed before and after RT. We evaluated the changes in the SMI, nutrition, and inflammatory factors between the patient group that used the mobile app (mHealth group) and our previous study cohort (usual care group). Additionally, we analyzed the factors associated with walk steps recorded in the app.
\end{abstract}

Results: Two patients dropped out of the study (no app usage; treatment changed to a definitive aim). The use (or activation) of the app was noted in approximately 70\% (25/36) of the patients until the end of the trial. Compared to the 1:2 matched usual care group by propensity scores balanced with their age, primary tumor location, tumor stage, pre-RT BMI, and pre-RT SMI level, 30 operable patients showed less aggravation of the prognostic nutritional index (PNI) ( 6.7 vs $-9.8 ; P=.04)$. However, there was no significant difference in the SMI change or the number of patients with excessive muscle loss $(\Delta \mathrm{SMI} / 50$ days $>10 \%)$. In patients with excessive muscle loss, the walk steps significantly decreased in the last 4 weeks compared to those in the first 4 
weeks. Age affected the absolute number of walk steps $(P=.01)$, whereas pre-RT sarcopenia was related to the recovery of the reduced walk steps $(P=.03)$.

Conclusions: For esophageal cancer patients receiving NACRT, a health care mobile app helped nutritional self-care with less decrease in the PNI, although it did not prevent excessive muscle loss. An individualized care model with proper exercise as well as nutritional support may be required to reduce muscle loss and malnutrition.

(J Med Internet Res 2021;23(8):e28695) doi: 10.2196/28695

\section{KEYWORDS}

esophageal cancer; malnutrition; muscle loss; sarcopenia; mobile app; mHealth

\section{Introduction}

Esophageal cancer is one of the most aggressive malignancies and is ranked as the sixth leading cause of cancer-related death worldwide [1]. Recent advances in treatment including radiotherapy (RT), chemotherapy, and surgery, and their combinations have led to improved clinical outcomes; however, patients continue to experience high mortality [2]. Patients with esophageal cancer commonly have symptoms such as dysphagia and weight loss even before a confirmed diagnosis of the disease, and up to $80 \%$ of patients are nutritionally compromised $[3,4]$. Malnutrition, cachexia, and sarcopenia are reported as poor prognostic factors associated with treatment compliance and clinical outcomes in esophageal cancer and various cancers other as well $[5,6]$.

Previously, we conducted a retrospective review among 248 esophageal cancer patients who underwent surgery and reported excessive muscle loss after neoadjuvant concurrent chemoradiotheapy (NACRT) as a significant poor prognostic factor for disease recurrence and overall survival [7]. In that study, many patients experienced malnutrition before and after NACRT; $62.9 \%$ of the patients were assigned the status of sarcopenia before the start of the treatment, and $28.2 \%$ showed more than $10 \%$ deterioration in the skeletal muscle index (SMI) after NACRT. To reduce muscle loss, more active support toward the patient's nutrition and physical activity was needed than education from a physician or nutrition specialist. Additionally, most patients were managed in the outpatient setting.

Noom (Noom Inc) [8] is one of the most popular commercial health care mobile apps. This app has been mainly used by obese people for weight control $[9,10]$. In addition to losing weight, the company also provides paramedical experience for patients with diabetes or eating disorders, and pregnant women [11-14]. It provides interactive health coaching on various aspects of nutrition, exercise, and weight control. Although there is little evidence for the usage of this app, it can be applied to the self-management of nutrition for cancer patients.

This prospective pilot study aimed to evaluate the usefulness of a health care mobile app in preventing malnutrition and excessive muscle loss in patients with esophageal cancer receiving NACRT.

\section{Methods}

\section{Study Design}

The inclusion criteria for this study were as follows: adult male patients (1) newly diagnosed with esophageal cancer, (2) scheduled for NACRT followed by radical surgery as per the authors' institutional protocol, and (3) undergoing positron emission tomography-computed tomography (PET-CT) as part of the diagnostic workup (Figure 1). Patients with synchronous distant metastasis, previous history of thoracic irradiation, or having difficulty using an app on a smartphone were excluded. Between July 2019 and May 2020, totally 38 patients were enrolled in this study. Data regarding the app usage were gathered for 8 weeks from the beginning of NACRT. During the trial, two patients dropped out; one did not use the app at all, and the other decided not to undergo surgery during NACRT and continued RT with a definitive aim for 6 weeks. Finally, 36 patients analyzed to evaluate the feasibility and effectiveness of using the app. This study was approved by the Institutional Review Board of Samsung Medical Center, and all participants provided written informed consent. 
Figure 1. Flowchart of the study design. CCRT: concomitant radiotherapy and chemotherapy; NACRT: neoadjuvant chemoradiotherapy; PET-CT: positron emission tomography-computed tomography.
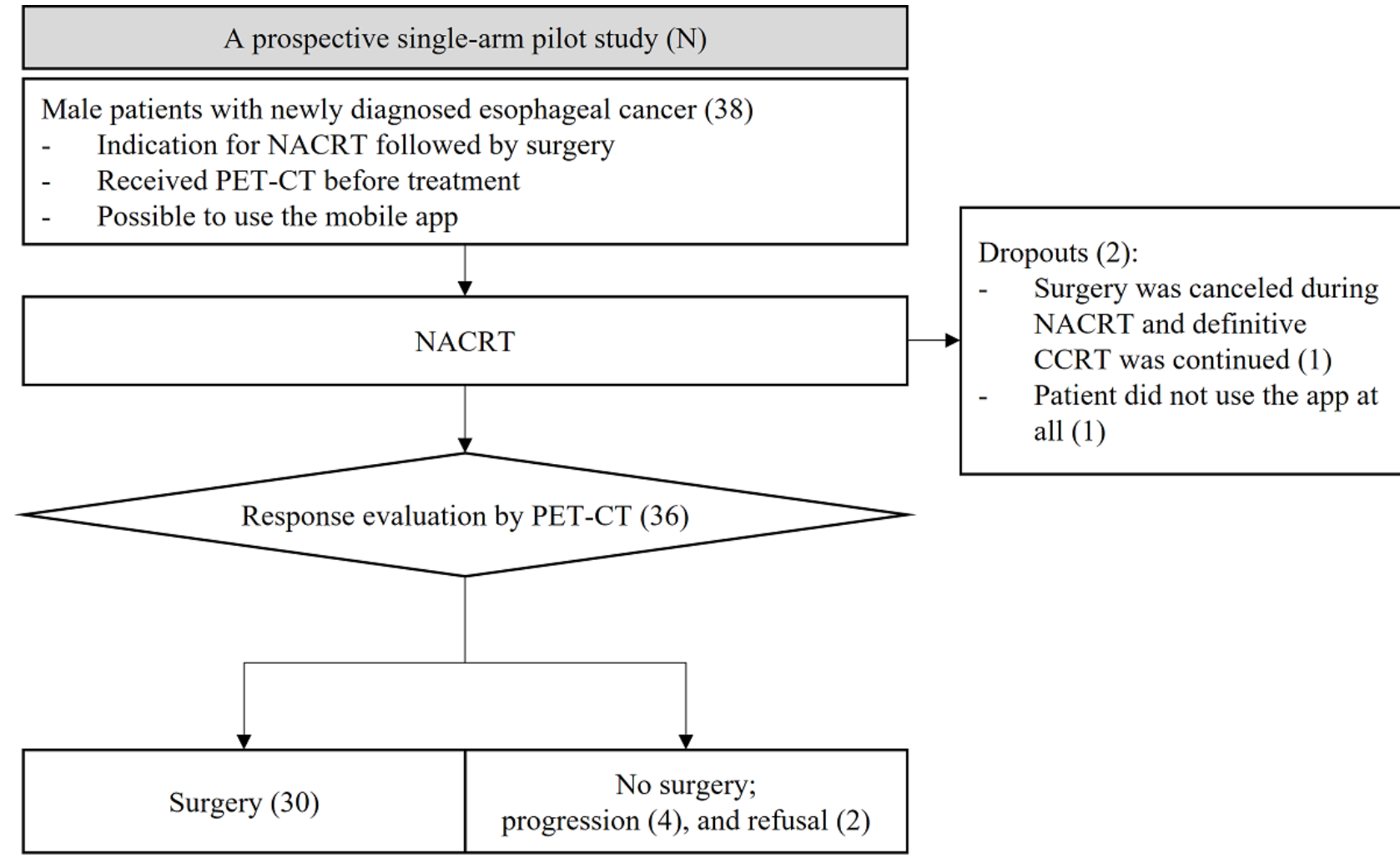

\section{Treatment Scheme}

Details of the treatment scheme, which includes RT and chemotherapy for NACRT, are described in our previous research [7]. The dose prescriptions for RT were $44 \mathrm{~Gy}$ in 22 fractions (2.0 Gy per fraction) for 18 patients and $43 \mathrm{~Gy}$ in 20 fractions (2.15 Gy per fraction) for 18 patients. All patients underwent intensity-modulated RT. All the patients completed NACRT as scheduled without grade 4 or higher complications. The concurrent chemotherapeutic regimen involved 2 cycles of cisplatin-based therapy in combination with 5-fluorouracil or capecitabine during RT. For response evaluation of NACRT, PET-CT was performed 3-4 weeks after the completion of NACRT, before surgery. The median time interval between pre-RT and post-RT PET-CTs was 73 days, ranging from 54 to 103 days. Patients underwent radical thoracic surgery, and the mean interval between the beginning of RT and completion of surgery was 10.5 weeks (range 9.1-14 weeks). Finally, surgery was not performed in 6 patients; 4 patients showed progressive disease after NACRT, not to assure curative surgery, and 2 patients did not want to undergo surgery after NACRT. Before NACRT, prophylactic feeding tube insertion was not performed in all patients except 1. During the trial, all patients received the best supportive care for their symptoms, such as painkillers and antacid drugs if needed.

\section{Mobile App for Health Coaching}

Before the start of NACRT, patients were informed about the trial and app usage by a study instructor and attended an online meeting with the app manager. The app provided services following enrollment, and the patients used it autonomously. The app setting was similar to that used in previous studies [9].
During the first sign-in, patients set their information including age, sex, height, and current and target weight. Users could record their food intake, exercise, and weight on a daily basis. In addition, the activity monitor in the app automatically measured the number of walk steps. Based on these records, the app provided summaries on calorie balance and weight trends. Additionally, experts in nutrition and exercise therapy provided feedback messages and encouraged the users through the app. The number of active records and messages from patients was counted each week in terms of nutrition, weight, and exercise. If any active data were recorded by the patient in a certain week, then the app was considered "activated" for that week. Based on previous experiences of the app users, as the compliance for this trial, the activation level of the app per 8 weeks was categorized as follows: "high," activated for 6-8 weeks; "moderate," activated for 4-5 weeks; and "low," activated for 1-3 weeks.

\section{Muscle Loss and Malnutrition Assessment}

Similar to our previous study, the skeletal muscle area $\left(\mathrm{cm}^{2}\right)$ at the level of the third lumbar vertebra (L3) in the two CT image sets from PET-CT before and after NACRT was measured using an in-house software program [15]. The SMI $\left(\mathrm{cm}^{2} / \mathrm{m}^{2}\right)$ was calculated from the skeletal muscle area divided by the square of the height $\left(\mathrm{m}^{2}\right)$. We also used the cutoff value of $52.4 \mathrm{~cm}^{2} / \mathrm{m}^{2}$ for sarcopenia from our previous study [7] and a population-based study [16]. $\Delta \mathrm{SMI}(\%)$, which is the percentage of SMI change based on the pre-RT SMI, was adjusted with various time intervals between 2 PET-CT measurements, and unified in 50 days per interval between 2 PET-CT measurements for each patient $(\Delta \mathrm{SMI} / 50$ days, $\%)$. Excessive muscle loss was defined when $\Delta \mathrm{SMI} / 50$ days was more than $10 \%$. 
Other information regarding nutritional status was obtained from the laboratory tests on the day closest to that before the start of RT (pre-RT) and those as preoperative workups (post-RT), which were the first blood tests in most patients performed after the end of RT. Data were collected for the following laboratory parameters: absolute counts of white blood cells $(\mathrm{WBC}, / \mu \mathrm{L})$, absolute neutrophil count $(\mathrm{ANC}, / \mu \mathrm{L})$, absolute lymphocyte count (ALC, / $\mu \mathrm{L})$, platelet count $(/ \mu \mathrm{L})$, and albumin level $(\mathrm{g} / \mathrm{dL})$. From these results, the neutrophil-to-lymphocyte ratio (NLR, ANC/ALC), platelet-to-lymphocyte ratio (platelet/ALC), and prognostic nutritional index $(\mathrm{PNI}, 10 \times$ albumin $+0.005 \times$ ALC) [17] were calculated.

\section{Statistical Analyses}

The purpose of this study was to evaluate whether $\Delta \mathrm{SMI}(\% / 50$ days) was reduced in patients who used the mobile app (mHealth group) compared with that in our previous study cohort (usual care group). Additionally, changes in nutritional and inflammatory factors were also analyzed between the two groups. To compare the two groups, propensity score matching was used to balance characteristics such as the age, primary tumor location, tumor stage, pre-RT BMI, and pre-RT SMI level. Fisher tests for discrete variables and $t$ tests (or Mann-Whitney $U$ test) for continuous variables were conducted for comparing the characteristics. To identify significant factors associated with excessive muscle loss in this study, logistic regression was performed with the quantified app data. Additionally, we performed mixed model analysis for repeated measures of walk steps counted by the app for 8 weeks. R 4.0.3 (version 4.0.3, R Development Core Team) [18] and SPSS Statistics (version 27.0, IBM Corp) were used for statistical analyses with $P<.05$ suggesting statistical significance.

\section{Results}

\section{Compliance With the App}

For 8 weeks of the trial, $80.6 \%$ (29/36), $77.8 \%$ (28/36), $75.0 \%$ (27/36), 77.8\% (28/36), 72.2\% (26/36), 66.7\% (24/36), and $72.2 \%(26 / 36)$ of the patients had been active on the app from the second week to the 8th week. In addition, the activation levels were as follows: high, moderate, and low levels in 25 $(69.4 \%), 3(8.3 \%)$, and $8(22.2 \%)$ patients, respectively. However, the patients selectively used parts of the app (Table 1). The most activated records were for the nutritional part. However, in the exercise records, only one was moderately activated, and there was no highly activated patient. Walk steps were passively gathered and had a pattern similar to that of the total activation level.

Table 1. Activation level based on the number of activated weeks.

\begin{tabular}{|c|c|c|c|}
\hline \multirow[t]{2}{*}{ Activated part of the app } & \multicolumn{3}{|c|}{ Activation level $^{\mathrm{a}}, \mathrm{n}(\%)(\mathrm{N}=36)$} \\
\hline & Low & Moderate & High \\
\hline At least one activation in any part of the app & $8(22.2)$ & $3(8.3)$ & $25(69.4)$ \\
\hline Nutrition & $14(38.8)$ & $7(19.4)$ & $15(41.7)$ \\
\hline Weight & $2055.6)$ & $4(11.1)$ & $12(33.3)$ \\
\hline Exercise & $35(97.2)$ & $1(2.8)$ & $0(0)$ \\
\hline Walking ${ }^{\mathrm{b}}$ & $6(16.7)$ & $5(13.9)$ & $25(69.4)$ \\
\hline
\end{tabular}

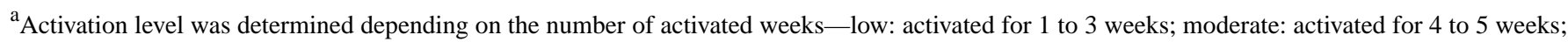
high: activated for 6 to 8 weeks.

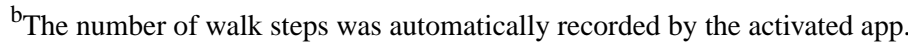

\section{Patient Characteristics and Comparison With the Usual Care Group}

The median patient age was 59 years, and all patients had an Eastern Cooperative Oncology Group Performance Status (ECOG PS) of 0 to 1 . The details of the patient characteristics are summarized in Table 2. Compared to the previous study cohort (usual care group), the age, tumor location, and some of the laboratory markers were significantly different in this study cohort (mHealth group) (Supplement table). As a result, $\Delta \mathrm{SMI} / 50$ days $(\%)$ and the proportion of patients with excessive muscle loss $(\Delta \mathrm{SMI} / 50$ days $>10 \%)$ were not significantly different between the two groups. However, in the mHealth group, the PNI decreased to a lesser extent after NACRT.

After 1:2 propensity score matching to adjust for variables such as the age, primary tumor location, tumor stage, pre-RT BMI, and pre-RT SMI level, we compared 30 patients in the mHealth group with those of the usual care group (Table 2). Even after propensity score matching, $\Delta \mathrm{SMI} / 50$ days $(\%)$ and the proportion of patients with excessive muscle loss $(\Delta \mathrm{SMI} / 50$ days $>10 \%)$ were not significantly different $(-8.1 \%$ vs $7.4 \%$, $P=.57$ and $33.3 \%$ vs $30.0 \%, P=.94$, respectively). The PNI decreased to a lesser extent in the mHealth group than in the usual care group ( -6.7 vs $-9.8, P=.04)$. 
Table 2. Propensity score matching and comparison in 30 patients who underwent surgery after neoadjuvant concurrent chemoradiotherapy.

\begin{tabular}{|c|c|c|c|}
\hline Characteristics & Previous cohort [7] $(n=60)$ & mHealth group $(n=30)^{\mathrm{a}}$ & $P$ value \\
\hline Age (years), median (SD) & $58.5(7.8)$ & $59.2(6.5)$ & .8 \\
\hline Age group, n (\%) & & & .99 \\
\hline$<60$ years & $34(56.7)$ & $17(56.7)$ & \\
\hline$\geq 60$ years & $26(43.3)$ & $13(43.3)$ & \\
\hline Smoking status, n (\%) & & & .41 \\
\hline Current smoker & $35(58.3)$ & $14(46.7)$ & \\
\hline Ex- or nonsmoker & $25(41.7)$ & $16(53.3)$ & \\
\hline Tumor location, n (\%) & & & .73 \\
\hline Upper & $12(20)$ & $4(13.3)$ & \\
\hline Middle & $21(35)$ & $11(36.7)$ & \\
\hline Lower & $27(45)$ & $15(50)$ & \\
\hline cT stage $\mathbf{b}^{\mathrm{b}}, \mathrm{n}(\%)$ & & & .49 \\
\hline $1-2$ & $24(40)$ & $9(30)$ & \\
\hline $3-4$ & $36(60)$ & $21(70)$ & \\
\hline cN stage ${ }^{c}, n(\%)$ & & & .94 \\
\hline $0-1$ & $34(56.7)$ & $18(60)$ & \\
\hline $2-3$ & $26(43.3)$ & $12(40)$ & \\
\hline Pre-RT ${ }^{\mathrm{d}}$ BMI $\left(\mathrm{kg} / \mathrm{m}^{2}\right)$, mean $(\mathrm{SD})$ & $22.9(2.8)$ & $22.9(2.3)$ & .99 \\
\hline Pre-RT BMI $\left(\mathrm{kg} / \mathrm{m}^{2}\right)$ & & & .99 \\
\hline$<20, \mathrm{n}(\%)$ & $7(11.7)$ & $3(10)$ & \\
\hline$\geq 20, \mathrm{n}(\%)$ & $53(88.3)$ & $27(90)$ & \\
\hline Post-RT BMI $\left(\mathrm{kg} / \mathrm{m}^{2}\right)$, mean (SD) & $22(6)$ & $21.8(2.6)$ & .65 \\
\hline \multicolumn{4}{|l|}{ Post-RT BMI $\left(\mathrm{kg} / \mathrm{m}^{2}\right)$} \\
\hline$<20, \mathrm{n}(\%)$ & $10(16.7)$ & $7(23.3)$ & .63 \\
\hline$\geq 20, \mathrm{n}(\%)$ & $50(83.3)$ & $23(76.7)$ & \\
\hline$\Delta \mathrm{BMI}\left(\mathrm{kg} / \mathrm{m}^{2}\right)$, mean $(\mathrm{SD})$ & $-0.8(1.4)$ & $-1.1(1.2)$ & .38 \\
\hline Pre-RT SMI $\left(\mathrm{cm}^{2} / \mathrm{m}^{2}\right)$, mean (SD) & $51.0(9.1)$ & $51.3(6.2)$ & .87 \\
\hline Pre-RT SMI $\left(\mathrm{cm}^{2} / \mathrm{m}^{2}\right)$ & & & .99 \\
\hline Sarcopenia, n (\%) & $36(60)$ & $18(60)$ & \\
\hline Nonsarcopenia, n (\%) & $24(40)$ & $12(40)$ & \\
\hline Post-RT SMI $\left(\mathrm{cm}^{2} / \mathrm{m}^{2}\right)$, mean (SD) & $45(7.8)$ & $45.9(6.9)$ & .58 \\
\hline Post-RT SMI $\left(\mathrm{cm}^{2} / \mathrm{m}^{2}\right)$ & & & .93 \\
\hline Sarcopenia, n (\%) & $48(80)$ & $23(76.7)$ & \\
\hline Nonsarcopenia, n (\%) & $12(20)$ & $7(23.3)$ & \\
\hline$\Delta \mathrm{SMI}$ (/50 days), mean, $\%$ (SD) & $-8.1(5.3)$ & $-7.4(6.5)$ & .57 \\
\hline$\Delta \mathrm{SMI}$ (/50 days) & & & .94 \\
\hline Decreased $>10 \%, \mathrm{n}(\%)$ & $20(33.3)$ & $9(30)$ & \\
\hline Decreased <10\%, n $(\%)$ & $40(66.7)$ & $21(70)$ & \\
\hline
\end{tabular}




\begin{tabular}{|c|c|c|c|}
\hline Characteristics & Previous cohort [7] $(\mathrm{n}=60)$ & mHealth group $(n=30)^{\mathrm{a}}$ & $P$ value \\
\hline \multicolumn{4}{|c|}{$\mathrm{WBC}^{\mathrm{f}}\left(\times 10^{3} / \mu \mathrm{L}\right)$, mean $(\mathrm{SD})$} \\
\hline Pre-RT & $8.2(2.5)$ & $7.1(1.7)$ & .02 \\
\hline Post-RT & $4.8(2.2)$ & $4.7(2.8)$ & .93 \\
\hline$\Delta$ & $-3.4(3.5)$ & $-2.3(2.8)$ & .05 \\
\hline \multicolumn{4}{|c|}{$\mathrm{ANC}^{\mathrm{g}}\left(\times 10^{3} / \mu \mathrm{L}\right)$, mean $(\mathrm{SD})$} \\
\hline Pre-RT & $5.1(2.2)$ & $4.4(1.3)$ & .2 \\
\hline Post-RT & $2.8(2)$ & $2.6(1.6)$ & 6 \\
\hline$\Delta$ & $-2.4(3.1)$ & $-1.8(2.1)$ & .34 \\
\hline \multicolumn{4}{|c|}{$\operatorname{ALC}^{\mathrm{h}}\left(\times 10^{3} / \mu \mathrm{L}\right)$, mean $(\mathrm{SD})$} \\
\hline Pre-RT & $2.2(0.5)$ & $1.9(0.6)$ & .02 \\
\hline Post-RT & $1.3(0.6)$ & $1.5(1.3)$ & 6 \\
\hline$\Delta$ & $-0.9(0.7)$ & $-0.4(1.3)$ & .11 \\
\hline \multicolumn{4}{|c|}{ Platelet $\left(\times 10^{3} / \mu \mathrm{L}\right)$, mean $(\mathrm{SD})$} \\
\hline Pre-RT & $263.0(72.2)$ & $260.3(52.9)$ & .86 \\
\hline Post-RT & $215.0(70.3)$ & $203.5(74)$ & .48 \\
\hline$\Delta$ & $-48.0(69.3)$ & $-56.7(84.2)$ & 6 \\
\hline \multicolumn{4}{|c|}{ Albumin (g/dL), mean (SD) } \\
\hline Pre-RT & $4.4(0.3)$ & $4.4(0.3)$ & .19 \\
\hline Post-RT & $3.8(0.5)$ & $4.0(0.4)$ & .07 \\
\hline$\Delta$ & $-0.6(0.4)$ & $-0.5(0.4)$ & .34 \\
\hline \multicolumn{4}{|c|}{ NLR ${ }^{i},>$ mean (SD) } \\
\hline Pre-RT & $2.4(1.0)$ & $2.5(1)$ & .77 \\
\hline Post-RT & $2.8(3.7)$ & $3.1(4.7)$ & .75 \\
\hline$\Delta$ & $0.4(3.9)$ & $0.6(5.1)$ & .82 \\
\hline \multicolumn{4}{|c|}{ PLR $^{\mathrm{j}}$, mean (SD) } \\
\hline Pre-RT & $125.3(41.8)$ & $149.8(54.1)$ & .02 \\
\hline Post-RT & 209.4 (159.6) & $212.1(160.8)$ & .94 \\
\hline$\Delta$ & 84.1 (157.6) & $62.4(173.4)$ & .55 \\
\hline \multicolumn{4}{|c|}{ PNI $^{\mathbf{k}}$, mean (SD) } \\
\hline Pre-RT & $54.6(4.2)$ & $54(4.2)$ & .54 \\
\hline Post-RT & $44.8(5.7)$ & $47.3(7.7)$ & .09 \\
\hline$\Delta$ & $-9.8(6)$ & $-6.7(7.5)$ & .04 \\
\hline
\end{tabular}

${ }^{\mathrm{a}}$ Patients who received surgery.

b $\mathrm{cT}$ : clinical tumor stage.

${ }^{\mathrm{c}} \mathrm{cN}$ : clinical nodal stage.

${ }^{\mathrm{d}} \mathrm{RT}$ : radiotherapy.

${ }^{\mathrm{e}} \mathrm{SMI}$ : skeletal muscle index.

${ }^{f}$ WBC: white blood cells.

$\mathrm{g}_{\text {ANC: absolute neutrophil count. }}$

${ }^{\mathrm{h}}$ ALC: absolute lymphocyte count.

${ }^{\mathrm{i}} \mathrm{NLR}$ : neutrophil-to-lymphocyte ratio.

${ }^{\mathrm{j}}$ PLR: platelet-to-lymphocyte ratio.

${ }^{\mathrm{k}} \mathrm{PNI}$ : prognostic nutritional index. 


\section{Use of the App and the Associated Excessive Muscle} Loss

In this study, there was excessive muscle loss in 12 of the 36 patients $(33.3 \%)$ (Table 3). Regarding the app usage, there was no significant difference in the activation level, but walk steps decreased more in the excessive muscle loss group. More patients with a $70 \%$ or more decrease in walk steps between the first and the last 4 weeks were in the excessive muscle loss group (66.7\% (6/9) vs $14.3 \%(3 / 21), P=.02)$.

Table 3. App usage and excessive muscle loss.

\begin{tabular}{|c|c|c|c|}
\hline App usage & $\begin{array}{l}\text { Nonexcessive muscle loss } \\
\text { group }(n=24)\end{array}$ & $\begin{array}{l}\text { Excessive muscle loss group } \\
(\mathrm{n}=12)\end{array}$ & $P$ value \\
\hline App activation level, $n(\%)$ & & & .96 \\
\hline Low & $5(20.8)$ & $3(25)$ & \\
\hline Moderate & $2(8.3)$ & $1(8.3)$ & \\
\hline High & $17(70.8)$ & $8(66.7)$ & \\
\hline First to fourth week, n (\%) & & & .99 \\
\hline No full activation & $6(25)$ & $3(25)$ & \\
\hline Full activation & $18(75)$ & $9(75)$ & \\
\hline Fifth to eighth week, n (\%) & & & .11 \\
\hline No full activation & $6(25)$ & $7(58.3)$ & \\
\hline Full activation & $18(75)$ & $5(41.7)$ & \\
\hline \multicolumn{4}{|l|}{ Walk steps $^{\text {a }}$} \\
\hline Steps per week $/ 10^{3}$, mean (SD) & $15.8(13.1)$ & $16.8(17)$ & .85 \\
\hline First to fourth week (a), mean (SD) & $16.9(13.2)$ & $18.4(18.2)$ & .79 \\
\hline Fifth to eighth week (b), mean (SD) & $10.4(10.5)$ & $5.6(9)$ & .22 \\
\hline$\Delta(\mathrm{b}-\mathrm{a}, \%)$, mean $(\mathrm{SD})$ & $-33.1(64.4)$ & $-69.0(35.5)$ & .13 \\
\hline Decrease $<70 \%, \mathrm{n}(\%)$ & $18(85.7)$ & $3(33.3)$ & .02 \\
\hline Decrease $>70 \%, \mathrm{n}(\%)$ & $3(14.3)$ & $6(66.7)$ & - b \\
\hline
\end{tabular}

${ }^{a}$ Nonexcessive muscle loss group ( $\left.n=21\right)$; excessive muscle loss group $(n=9)$.

${ }^{\mathrm{b}}$ Not applicable.

\section{Mixed Model Analysis for Weekly Walk Steps}

Repeatedly measured walk steps appeared to have a pattern (Figure 2A), which decreased at the 5th and 6th weeks and slightly recovered at the 7th and 8th weeks. Discrete variables such as age, BMI, SMI, and surgery were used for this analysis (Table 4). When the variables were fixed, time (week) was commonly significant. In contrast, when time was fixed, only the age was significantly different $(P=.01)$, which showed a gap in the absolute number of walk steps in the two age groups (Figure 2B). For the interaction between time and each variable, only pre-RT sarcopenia was significantly different $(P=.03)$, which showed different recovery patterns at the 6th and 8th weeks between the pre-RT sarcopenia and nonsarcopenia groups (Figure 2C). Although not significant, excessive muscle loss seemed to affect the trend in the number of walk steps (Figure 2D). 
Figure 2. Weekly trends in walk steps recorded automatically by the application for 8 weeks ( $N=33$ ): all patients (A), patient groups according to age (B), pre-RT sarcopenia (C), and excessive muscle loss (- $\Delta \mathrm{SMI} / 50$ days $>10 \%)$, during neoadjuvant concurrent chemoradiotherapy. RT: radiotherapy; SMI: skeletal muscle index.

(A)

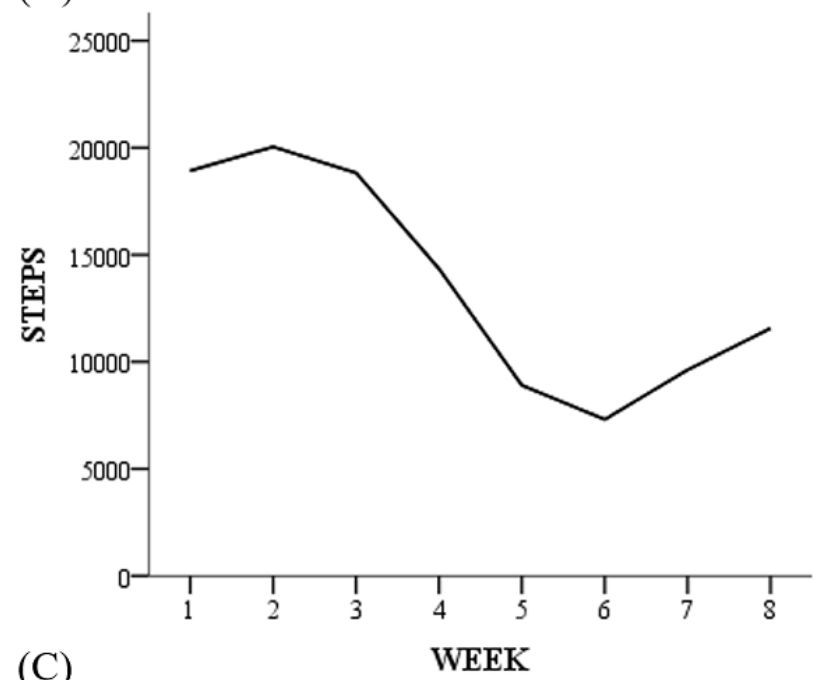

(C)

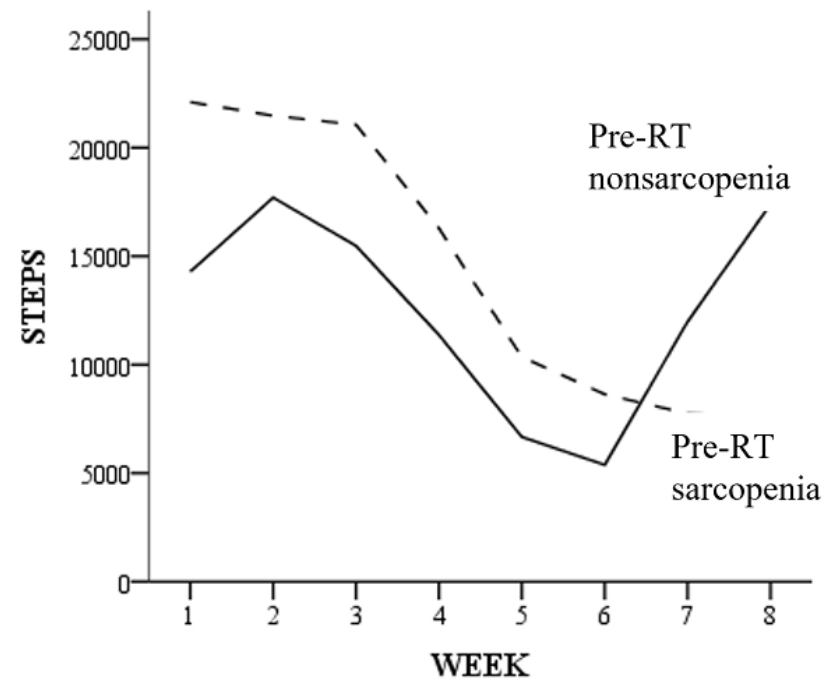

(B)
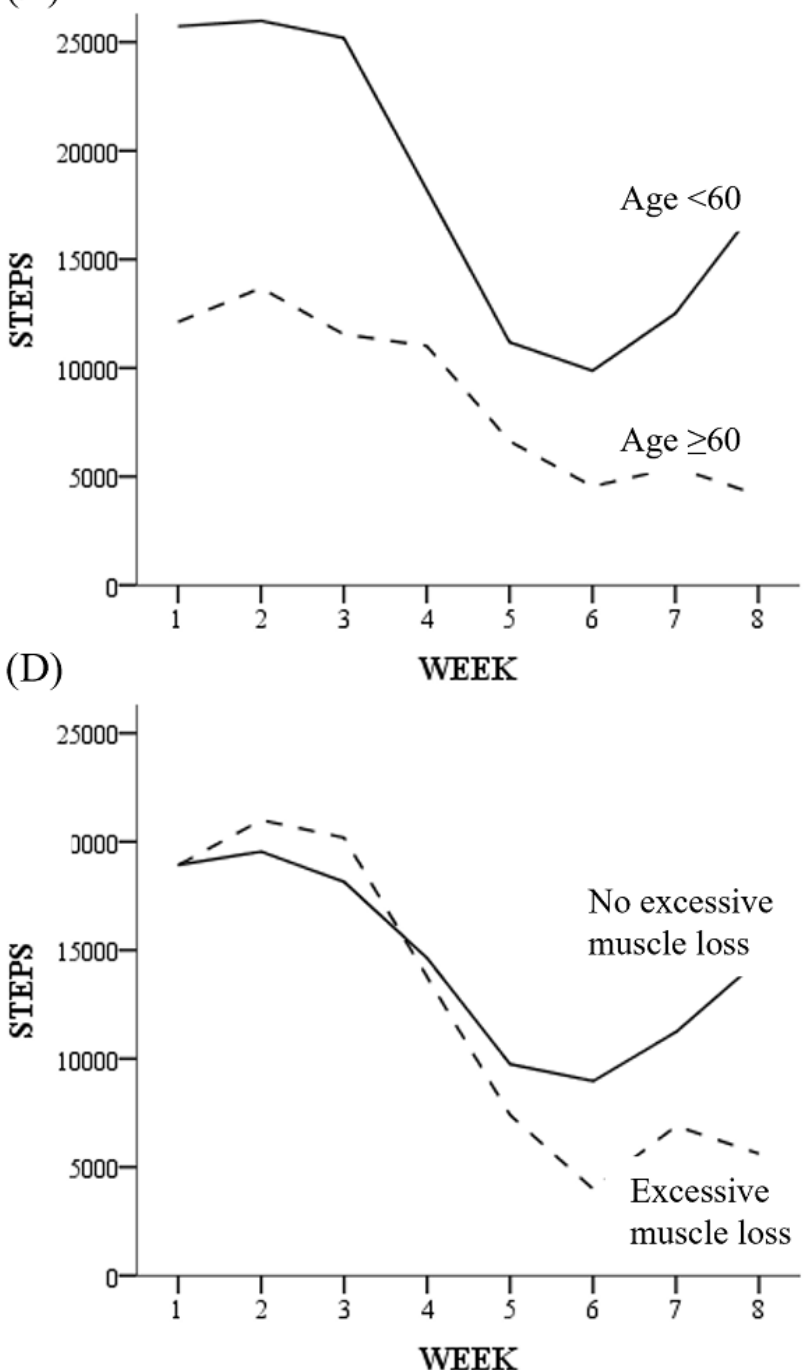

Table 4. Mixed model analysis with walk steps for 8 weeks.

\begin{tabular}{llll}
\hline For 8 weeks & $P$ value for weeks & $P$ value for variables & $P$ value for interaction \\
\hline Age $(<60$ vs $\geq 60$ years $)$ & $<.001$ & .006 & .39 \\
Pre-RT $\mathrm{BMI}\left(\geq 20 \mathrm{vs}<20 \mathrm{~kg} / \mathrm{m}^{2}\right)$ & .001 & .17 & .98 \\
Post-RT BMI $\left(\geq 20\right.$ vs $\left.<20 \mathrm{~kg} / \mathrm{m}^{2}\right)$ & .001 & .67 & .47 \\
$-\Delta$ BMI $\left(>5 \%\right.$ vs $\left.<5 \% \mathrm{~kg} / \mathrm{m}^{2}\right)$ & $<.001$ & .98 & .096 \\
Pre-RT sarcopenia $($ yes vs no) & $<.001$ & .55 & .03 \\
Post-RT sarcopenia (yes vs no) & .001 & .44 & .64 \\
$-\Delta$ SMI $/ 50$ days $>10 \%(>10 \%$ vs $<10 \%)$ & $<.001$ & .42 & .43 \\
Surgery (Yes vs No) & .007 & .08 & .96 \\
\hline
\end{tabular}

${ }^{\mathrm{a}} \mathrm{RT}$ : radiotherapy.

${ }^{\mathrm{b}}$ SMI: skeletal muscle index. 


\section{Discussion}

\section{Principal Findings}

Sarcopenia is a syndrome characterized by a progressive decrease in skeletal muscle mass and strength, leading to a risk of worse outcomes in terms of physical ability, quality of life, and survival, although there are various definitions for this term provided by the European Working Group on Sarcopenia in Older People (EWGSOP), the European Society for Clinical Nutrition and Metabolism Special Interest Groups (ESPEN-SIG), and the International Working Group on Sarcopenia (IWGS) [19]. It was first considered an age-related disease by Rosenberg [20]. However, in recent years, it is clinically noticeable that sarcopenia can be caused by malignancy or inflammatory diseases and adversely affects their treatment. The mechanism of sarcopenia is not clear but seems multifactorial; its risk factors are old age; female sex; low level of physical activity; and comorbidities including malignancy, obesity, osteoporosis, and diabetes [21]. Focusing on malignancy, higher metabolism, and inflammation by aggressive cancer cells, cancer treatments including surgery, chemotherapy, and RT; anorexia or poor oral intake; and low physical activity make patients more susceptible to sarcopenia [22]. Moreover, gastrointestinal malignancy easily causes malnutrition, and most esophageal cancer patients experience cachexia or sarcopenia. Furthermore, the presence of sarcopenia in cancer patients has been accepted clinically as one of the important predictors of survival and treatment outcomes [6,22]. In addition to clinical evidence, the muscle loss is gaining interest in biochemical research, including the anti-inflammatory or anticancer effects of myokines [23]. We previously analyzed the effect of sarcopenia in patients with esophageal cancer receiving NACRT [7]. NACRT itself has risk factors for sarcopenia; symptoms or complications such as nausea/vomiting and anorexia induced by chemotherapy and acute esophagitis by RT can deplete nutrition and physical energy [22]. We revealed that the changes in the muscle index ( $\Delta \mathrm{SMI} / 50$ days) were the prognostic factors for disease recurrence and survival and not the presence of sarcopenia before the treatment [7]. Additionally, sarcopenia is related to nutritional and inflammatory markers [7,24]. Therefore, we suggest that appropriate intervention for nutrition and physical activity could be beneficial for these patients.

Numerous interventions to overcome malnutrition in patients with various cancers have been attempted $[3,25,26]$. Unfortunately, interventions to improve cancer patients' malnutrition or muscle loss have been rare. Malnutrition is still considered insurmountable, and most esophageal cancer patients find it difficult to overcome malnutrition or often experience worsened conditions. This study, which used an interactive health coaching mobile app as an intervention for nutrition and physical activity, found similar negative results in terms of preventing muscle loss in esophageal cancer patients receiving NACRT compared to that in the usual care group. As a secondary endpoint, however, the use of the mobile app could improve nutritional indicators such as PNI, which is also known to be a prognostic factor for gastrointestinal cancers [17]. The compliance of the mobile app was as good because $70 \%$ (20/36) of the patients used it until the end of the trial, especially in nutrition and weight items. This could be because the patients were concerned about maintaining their oral intake and weight.

Guidelines for nutritional support suggest that appropriate interventions have to be selected depending on each patient's nutritional status, from basic nutritional modification and oral nutritional supplements to enteral or parenteral nutrition for severe cases $[3,5]$. However, it might be difficult by only through nutritional interventions to improve or prevent sarcopenia. The benefit of physical activity and exercise is well known for sarcopenia, and the international clinical practice guidelines for sarcopenia in 2018 strongly recommend physical activity for the treatment of sarcopenia [27]. Any single intervention in the aspect of nutrition, exercise, or medication is less effective for the management of sarcopenia, and proper dietary intake and exercise should be combined [28]. Resistance exercise has been shown to improve muscle mass and strength $[29,30]$.

An interesting result was the number of weekly walk steps. The mean of the walk steps reached a maximum of 20,000 in the second week and a minimum of 7000 in the 6th week. It is assumed that the limited physical activity during the fourth to the 6th week could cause muscle loss. This pattern is associated with the severity of radiation esophagitis. In general, RT esophagitis begins at week 2 of RT, its severity increases over time, and peaks at the end of RT. It takes approximately 3 weeks for the symptoms to resolve. Detailed analyses of the walking steps showed that patients with excessive muscle loss during NACRT significantly decreased the number of steps in the last half of the trial period. Furthermore, age affected the number of walking steps, and pre-RT sarcopenia showed a difference in the recovery of the decreased walking steps after NACRT. This means that older patients and those with sarcopenia at the start of the treatment have difficulty maintaining physical activity during the treatment and recovering decreased physical activity after NACRT. Some studies suggested that the number of walking steps was related to performance status [31]. As performance status is also one of the important factors for surgical indication and outcome [32], the pattern of the decrease and recovery in walking steps after NACRT is likely to be an indicator for the continuation of follow-up surgery or a predictor for postoperative mortality in patients with esophageal cancer.

To prevent malnutrition and muscle loss in esophageal cancer patients receiving NACRT, comprehensive supportive care including nutritional care as well as exercise might be needed. In addition, the status of nutrition and muscle mass needs to be evaluated individually before the start of treatment. For example, patients without malnutrition and sarcopenia can be managed with the mobile interactive coaching app used in this study. However, patients with old age, malnutrition, and sarcopenia might need to be managed differently. Physical activity guidelines for cancer patients from the American Cancer Society recommend avoiding inactivity, continuing normal daily activity as much as possible, and performing exercise adapted for the disease and the patients' condition, particularly if patients experience severe symptoms such as extreme fatigue or ataxia, or have cardiovascular and pulmonary contraindications [33]. However, exercise programs targeting patients with sarcopenia or extremely low physical activity are not well established, and 
high-intensity exercise might be not good for patients undergoing cancer treatment. It is necessary to develop a customized and intensity-modified physical program for patients with malnutrition and sarcopenia.

As a limitation, this prospective study was a small pilot test, thus limiting detailed analyses. We used the SMI from CT to diagnose sarcopenia, but muscle strength, which is one of the criteria for the definition of sarcopenia, could not be evaluated. In addition, all enrolled patients were male for comparison with our previous study, which predominantly involved esophageal cancer patients for ensuring study homogeneity. Finally, we focused on the app usage such as the activation or automatically recorded walk steps, but more specific nutritional factors such as calories during oral intake were missing. Although the app was not highly effective in preventing muscle loss and further research using more detailed information is needed, we expect that it can be used as a self-managing nutritional support for cancer patients and possibly expanded for cancer survivors after treatment.

\section{Conclusion}

For esophageal cancer patients receiving NACRT, an interactive health coaching mobile app helped nutritional self-care with a significantly less decrease in PNI, although it did not prevent excessive muscle loss. Low physical activity estimated by the number of walking steps did not recover even a few weeks after the end of NACRT in patients with old age or pretreatment sarcopenia. An individualized care model with proper exercise as well as nutritional support may be required to reduce muscle loss and malnutrition.

\section{Acknowledgments}

Noom Inc provided full range of services in the Noom app during this trial.

\section{Conflicts of Interest}

Although HK, JL, and YK are affiliated to the company providing the app, this study was based on only objective measures such as patient activities using the app, walk steps, and clinical data. The other authors have no conflict of interest to disclose.

\section{References}

1. Bray F, Ferlay J, Soerjomataram I, Siegel RL, Torre LA, Jemal A. Global cancer statistics 2018: GLOBOCAN estimates of incidence and mortality worldwide for 36 cancers in 185 countries. CA Cancer J Clin 2018 Nov;68(6):394-424 [FREE Full text] [doi: 10.3322/caac.21492] [Medline: $\underline{30207593]}$

2. van Hagen P, Hulshof M, van Lanschot J, Steyerberg E, Henegouwen MVB, Wijnhoven B, et al. Preoperative chemoradiotherapy for esophageal or junctional cancer. N Engl J Med 2012 May;366(22):2074-2084. [doi: 10.1056/nejmoa1112088]

3. Jordan T, Mastnak DM, Palamar N, Kozjek NR. Nutritional therapy for patients with esophageal cancer. Nutr Cancer 2017 Oct;70(1):23-29. [doi: 10.1080/01635581.2017.1374417] [Medline: 29016197]

4. Kirby DF, Teran JC. Enteral feeding in critical care, gastrointestinal diseases, and cancer. Gastrointest Endosc Clin N Am 1998 Jul;8(3):623-643. [Medline: 9654573 ]

5. Meier R, Forbes A. Basics in clinical medical nutrition. In: The Importance of Nutrition as an Integral Part of Disease Management. Basel: Karger; 2015 Presented at: 82nd Nestlé Nutrition Institute Workshop; October 2015; New Delhi p. 1-16. [doi: 10.1159/000381997]

6. Anandavadivelan P, Lagergren P. Cachexia in patients with oesophageal cancer. Nat Rev Clin Oncol 2015 Nov;13(3):185-198. [doi: 10.1038/nrclinonc.2015.200]

7. Yoon HG, Oh D, Ahn YC, Noh JM, Pyo H, Cho WK, et al. Prognostic impact of sarcopenia and skeletal muscle loss during neoadjuvant chemoradiotherapy in esophageal cancer. Cancers (Basel) 2020 Apr;12(4):925 [FREE Full text] [doi: 10.3390/cancers12040925] [Medline: 32290037]

8. https://www.noom.com. URL: https://www.noom.com [accessed 2021-08-04]

9. Chin SO, Keum C, Woo J, Park J, Choi HJ, Woo J, et al. Successful weight reduction and maintenance by using a smartphone application in those with overweight and obesity. Sci Rep 2016 Nov;6:34563 [FREE Full text] [doi: 10.1038/srep34563] [Medline: 27819345]

10. Jacobs S, Radnitz C, Hildebrandt T. Adherence as a predictor of weight loss in a commonly used smartphone application. Obes Res Clin Pract 2017 Mar;11(2):206-214. [doi: 10.1016/j.orcp.2016.05.001] [Medline: 27292942]

11. Gallagher D, Rosenn B, Toro-Ramos T, Paley C, Gidwani S, Horowitz M, et al. Greater neonatal fat-free mass and similar fat mass following a randomized trial to control excess gestational weight gain. Obesity 2018 Feb;26(3):578-587. [doi: 10.1002/oby.22079]

12. Michaelides A, Major J, Pienkosz E, Wood M, Kim Y, Toro-Ramos T. Usefulness of a novel mobile diabetes prevention program delivery platform with human coaching: 65-week observational follow-up. JMIR Mhealth Uhealth 2018 May;6(5):e93 [FREE Full text] [doi: 10.2196/mhealth.9161] [Medline: 29724709]

13. Hildebrandt T, Michaelides A, Mackinnon D, Greif R, DeBar L, Sysko R. Randomized controlled trial comparing smartphone assisted versus traditional guided self-help for adults with binge eating. Int J Eat Disord 2017 Nov;50(11):1313-1322 [FREE Full text] [doi: $\underline{10.1002 / \text { eat.22781] [Medline: 28960384] }}$ 
14. Toro-Ramos T, Michaelides A, Anton M, Karim Z, Kang-Oh L, Argyrou C, et al. Mobile delivery of the diabetes prevention program in people wth prediabetes: randomized controlled trial. JMIR Mhealth Uhealth 2020 Jul;8(7):e17842 [FREE Full text] [doi: $10.2196 / 17842]$ [Medline: $\underline{32459631}$ ]

15. https://sourceforge.net/projects/muscle-fatarea-measurement. URL: https://sourceforge.net/projects/ muscle-fatarea-measurement [accessed 2021-08-04]

16. Prado CMM, Lieffers JR, McCargar LJ, Reiman T, Sawyer MB, Martin L, et al. Prevalence and clinical implications of sarcopenic obesity in patients with solid tumours of the respiratory and gastrointestinal tracts: a population-based study. Lancet Oncol 2008 Jul;9(7):629-635. [doi: 10.1016/S1470-2045(08)70153-0] [Medline: 18539529]

17. Migita K, Takayama T, Saeki K, Matsumoto S, Wakatsuki K, Enomoto K, et al. The prognostic nutritional index predicts long-term outcomes of gastric cancer patients independent of tumor stage. Ann Surg Oncol 2013 Mar;20(8):2647-2654. [doi: 10.1245/s10434-013-2926-5]

18. http://www.R-project.org. URL: http://www.R-project.org [accessed 2021-08-04]

19. Santilli V, Bernetti A, Mangone M, Paoloni M. Clinical definition of sarcopenia. Clin Cases Miner Bone Metab 2014 Sep;11(3):177-180 [FREE Full text] [Medline: 25568649]

20. Rosenberg IH. Sarcopenia: origins and clinical relevance. Clin Geriatr Med 2011 Aug;27(3):337-339. [doi: 10.1016/j.cger.2011.03.003] [Medline: 21824550]

21. Gale CR, Martyn CN, Cooper C, Sayer AA. Grip strength, body composition, and mortality. Int J Epidemiol 2007 Mar;36(1):228-235. [doi: 10.1093/ije/dyl224] [Medline: 17056604]

22. Chindapasirt J. Sarcopenia in cancer patients. Asian Pac J Cancer Prev 2015 Jan;16(18):8075-8077 [FREE Full text] [doi: 10.7314/apjcp.2015.16.18.8075] [Medline: 26745041]

23. Roy P, Chowdhury S, Roy HK. Exercise-induced myokines as emerging therapeutic agents in colorectal cancer prevention and treatment. Future Oncol 2018 Feb;14(4):309-312 [FREE Full text] [doi: 10.2217/fon-2017-0555] [Medline: 29318900]

24. Lin J, Zhang W, Huang Y, Chen W, Wu R, Chen X, et al. Sarcopenia is associated with the neutrophil/lymphocyte and platelet/lymphocyte ratios in operable gastric cancer patients: a prospective study. CMAR 2018 Oct;10:4935-4944. [doi: 10.2147/cmar.s175421]

25. Foucaut A, Morelle M, Kempf-Lépine AS, Baudinet C, Meyrand R, Guillemaut S, et al. Feasibility of an exercise and nutritional intervention for weight management during adjuvant treatment for localized breast cancer: the PASAPAS randomized controlled trial. Support Care Cancer 2019 Sep;27(9):3449-3461. [doi: 10.1007/s00520-019-4658-y] [Medline: $\underline{\text { 30680617] }}$

26. Rinninella E, Cintoni M, Raoul P, Pozzo C, Strippoli A, Bria E, et al. Effects of nutritional interventions on nutritional status in patients with gastric cancer: a systematic review and meta-analysis of randomized controlled trials. Clin Nutr ESPEN 2020 Aug;38:28-42. [doi: 10.1016/j.clnesp.2020.05.007] [Medline: $\underline{\text { 32690170] }}$

27. Dent E, Morley JE, Cruz-Jentoft AJ, Arai H, Kritchevsky SB, Guralnik J, et al. International Clinical Practice Guidelines for Sarcopenia (ICFSR): screening, diagnosis and management. J Nutr Health Aging 2018 Nov;22(10):1148-1161. [doi: 10.1007/s12603-018-1139-9] [Medline: 30498820]

28. Cruz-Jentoft AJ, Sayer AA. Sarcopenia. The Lancet 2019 Jun;393(10191):2636-2646. [doi: 10.1016/s0140-6736(19)31138-9]

29. Peterson MD, Rhea MR, Sen A, Gordon PM. Resistance exercise for muscular strength in older adults: a meta-analysis. Ageing Res Rev 2010 Jul;9(3):226-237 [FREE Full text] [doi: 10.1016/j.arr.2010.03.004] [Medline: 20385254]

30. Peterson M, Sen A, Gordon P. Influence of resistance exercise on lean body mass in aging adults: a meta-analysis. Med Sci Sports Exerc 2011 Feb;43(2):249-258 [FREE Full text] [doi: 10.1249/MSS.0b013e3181eb6265] [Medline: 20543750]

31. Gresham G, Hendifar AE, Spiegel B, Neeman E, Tuli R, Rimel BJ, et al. Wearable activity monitors to assess performance status and predict clinical outcomes in advanced cancer patients. NPJ Digit Med 2018;1:27 [FREE Full text] [doi: 10.1038/s41746-018-0032-6] [Medline: 31304309]

32. Cihoric M, Tengberg LT, Foss NB, Gögenur I, Tolstrup M, Bay-Nielsen M. Functional performance and 30-day postoperative mortality after emergency laparotomy-a retrospective, multicenter, observational cohort study of 1084 patients. Perioper Med (Lond) 2020 May;9(1):13 [FREE Full text] [doi: 10.1186/s13741-020-00143-7] [Medline: 32391145]

33. Schmitz KH, Courneya KS, Matthews C, Demark-Wahnefried W, Galvão DA, Pinto BM, et al. American College of Sports Medicine roundtable on exercise guidelines for cancer survivors. Med Sci Sports Exerc 2010 Jul;42(7):1409-1426. [doi: 10.1249/MSS.0b013e3181e0c112] [Medline: 20559064]

\section{Abbreviations}

ALC: absolute lymphocyte count

ANC: absolute neutrophil count

ESOG PS: Eastern Cooperative Oncology Group Performance Status

ESPEN-SIG: European Society for Clinical Nutrition and Metabolism Special Interest Groups IWGS: International Working Group on Sarcopenia

EWGSOP: European Working Group on Sarcopenia in Older People

NACRT: neoadjuvant chemoradiotherapy 
NLR: neutrophil-to-lymphocyte ratio

PNI: prognostic nutritional index

RT: radiotherapy

SMI: skeletal muscle index

WBC: white blood cell

Edited by R Kukafka; submitted 11.03.21; peer-reviewed by SG Park, M Hamidzadeh; comments to author 19.04.21; revised version received 30.04.21; accepted 13.07.21; published 27.08.21

Please cite as:

Yang K, Oh D, Noh JM, Yoon HG, Sun JM, Kim HK, Zo JI, Shim YM, Ko H, Lee J, Kim Y

Feasibility of an Interactive Health Coaching Mobile App to Prevent Malnutrition and Muscle Loss in Esophageal Cancer Patients

Receiving Neoadjuvant Concurrent Chemoradiotherapy: Prospective Pilot Study

J Med Internet Res 2021;23(8):e28695

URL: https://www.jmir.org/2021/8/e28695

doi: $10.2196 / 28695$

PMID:

CKyungmi Yang, Dongryul Oh, Jae Myoung Noh, Han Gyul Yoon, Jong-Mu Sun, Hong Kwan Kim, Jae Ill Zo, Young Mog Shim, Hyunyoung Ko, Jungeun Lee, Youngin Kim. Originally published in the Journal of Medical Internet Research (https://www.jmir.org), 27.08.2021. This is an open-access article distributed under the terms of the Creative Commons Attribution License (https://creativecommons.org/licenses/by/4.0/), which permits unrestricted use, distribution, and reproduction in any medium, provided the original work, first published in the Journal of Medical Internet Research, is properly cited. The complete bibliographic information, a link to the original publication on https://www.jmir.org/, as well as this copyright and license information must be included. 